\title{
Desenvolvimento de metodologias ativas por meio do design thinking
}

\author{
Development of active-teaching methodologies through the design thinking \\ Desarrollo de metodologías activas mediante design thinking
}

Recebido: 13/10/2021 | Revisado: 23/10/2021 | Aceito: 26/10/2021 | Publicado: 29/10/2021

\author{
Elisa Queiroz dos Santos \\ ORCID: https://orcid.org/0000-0003-4650-5429 \\ Universidade Vale do Rio Verde, Brasil \\ E-mail: elikesantos@gmail.com \\ Letícia Rodrigues da Fonseca \\ ORCID: https://orcid.org/0000-0002-3528-2090 \\ Universidade Vale do Rio Verde, Brasil \\ E-mail: leticia.rodrigues.vga@gmail.com.br
}

\begin{abstract}
Resumo
Este estudo propôs como objetivo principal, produzir um curso de qualificação profissional que possibilite aos educadores compreender como aplicar e desenvolver metodologias de ensino ativas que favoreçam a aprendizagem significativa por meio do Design Thinking. Para isso, realizou-se uma pesquisa do tipo exploratória e descritiva e de abordagem qualitativa em uma Instituição de Educação Básica pública da região sul de Minas Gerais. Utilizou-se como método de coleta de dados a entrevista semiestruturada e para a análise de dados a codificação. Ao final, foi possível desenvolver um curso que buscou favorecer o entendimento sobre o modo de aplicação das principais metodologias ativas, bem como, o entendimento acerca do uso do Design Thinking para o desenvolvimento de tais metodologias.
\end{abstract}

Palavras-chave: Qualificação profissional; Metodologias ativas; Práticas de ensino inovadoras; Design thinking.

\begin{abstract}
This study proposes, as the main objective, to produce a professional qualification course that allows the educators to comprehend how to apply and develop active-teaching methodologies that enable meaningful learning through the Design Thinking. For this, an exploratory and descriptive research within an qualitative approach was carried out in a public basic education institution, located in the southern region of Minas Gerais. It was used as a data collection method, the semi-structured interview and, for the data analysis the codification method. At the end, it was possible to develop a qualification course that aimed to favor the understanding about the importance of applying active methodologies that allow meaningful learning, as well as, the understanding regarding the use of Design Thinking for the development of such methodologies.
\end{abstract}

Keywords: Professional qualification; Active methodologies; Innovative teaching practices; Design Thinking.

\section{Resumen}

Este estudio se propuso como objetivo principal producir un curso de calificación profesional que permita a los educadores comprender cómo aplicar y desarrollar metodologías de enseñanza activa que favorezcan el aprendizaje significativo a través del Design Thinking. Para ello, se realizó una investigación exploratoria y descriptiva con enfoque cualitativo en una Institución de Educación Básica pública de la región sur de Minas Gerais. La entrevista semiestructurada se utilizó como método de recopilación de datos y la codificación se utilizó para el análisis de datos. Al final, se pudo desarrollar un curso que buscó favorecer la comprensión de cómo aplicar las principales metodologías activas, así como la comprensión del uso del Design Thinking para el desarrollo de dichas metodologias.

Palavras clave: Calificación professional; Metodologías activas; Prácticas de enseñanza inovadoras; Design thinking.

\section{Introdução}

Considerando que a aquisição de conhecimentos que serão aplicados nos âmbitos profissional e social ocorrerá, principalmente, durante a formação escolar, é fundamental aos educadores rever os seus métodos de ensino com um olhar que vá além dos modelos tradicionais, para proporcionar uma aprendizagem significativa e vivencial e que possibilite a formação de indivíduos capazes de atender às atuais necessidades da sociedade. 
Este contexto justifica-se pelo acirramento da competitividade mundial, resultante do processo de globalização que exige grande capacidade de adaptabilidade às mudanças e respostas cada vez mais assertivas e inovadoras. Tal cenário, denominado 'economia do conhecimento', baseia-se na aplicação do conhecimento humano a tudo que se produz e à maneira como se produz, pois possibilita conceber produtos e serviços, desde o desenvolvimento até a entrega e apoio na utilização. Logo, o valor agregado é adquirido por meio da inteligência humana, ao invés do esforço físico de trabalhadores. Os ativoschave das organizações passam a ser os ativos inteligentes ou os trabalhadores do conhecimento que são capazes de desenvolver novos produtos e serviços conforme as atuais expectativas dos consumidores, como propor soluções para a melhoria da qualidade de vida da sociedade (Albertin, 2000).

Sendo assim, a formação escolar e universitária assume uma posição de grande importância, pois é ela que permitirá o desenvolvimento das competências, habilidades e atitudes requeridas pelo mundo do trabalho. Entretanto, para que este propósito seja atendido, não basta para a Instituição de Ensino - IE possuir professores com titulações e experiência acadêmica e, em alguns casos, profissional. É preciso que estes docentes sejam capazes de fazer uso de métodos de ensino que possibilitem o aprendizado significativo para que o aluno compreenda os motivos de se aprender determinados conteúdos e como aplicá-los. Portanto, pesquisas que busquem identificar e propor estratégias inovadoras para qualificar professores com o intuito de atender tal objetivo são pertinentes para este momento (Neves, Rodrigues, Bento, Maranhão, \& Neves, 2019; Augustinho \& Vieira, 2021).

Ressalta-se que, para aperfeiçoar a prática docente por meio da utilização de métodos inovadores que valorizam a aprendizagem significativa, é preciso, primeiramente, que as IEs acreditem e estejam dispostas a promover uma mudança cultural que busque superar valores que foram instituídos a partir do paradigma tradicional de ensino. Além disso, é preciso que as IEs invistam em capacitação profissional e em estrutura para que os professores possam conhecer e entender como aplicar essas metodologias em sua prática como docente (Lourenço, Alves, \& Silva, 2021).

Diante deste contexto, este estudo que originou-se de uma dissertação de Mestrado da área de Gestão, Planejamento e Ensino norteou-se pelo seguinte problema de pesquisa: como sensibilizar docentes da Educação Básica acerca da importância de se possibilitar aos seus alunos uma aprendizagem significativa por meio de metodologias ativas? Considerando esta problemática, se propôs como objetivo geral: desenvolver um curso de qualificação profissional que possibilite aos educadores compreender como aplicar e desenvolver metodologias de ensino ativas que favoreçam a aprendizagem significativa por meio do Design Thinking. Já, como objetivos específicos, buscou-se: (i) descrever a importância de se viabilizar uma aprendizagem significativa na Educação Básica; (ii) descrever as principais metodologias ativas que poderão ser utilizadas em sala de aula para favorecer a aprendizagem significativa; (iii) descrever como o Design Thinking contribuirá para o desenvolvimento de metodologias de ensino ativas; (iv) obter evidências acerca da efetividade deste curso de qualificação profissional quanto ao seu propósito formativo. Acrescenta-se que o Design Thinking trata-se de uma metodologia muito utilizada no âmbito organizacional que foca na empatia, colaboração e experimentação para estimular e promover a transformação e inovação em produtos e serviços por meio de seus métodos. Atualmente, vem sendo utilizada também no setor educacional com o intuito de favorecer o estabelecimento de inovações no âmbito da IE (Santos et al., 2017).

\section{Revisão teórica}

\subsection{A necessidade de uma ruptura paradigmática na educação}

Ainda é latente o processo de ensino e aprendizagem pautado no tradicionalismo da mecanicidade em aprender, no qual os alunos incumbem-se da memorização de conceitos depositados pelos professores em detrimento à motivação do pensar e do descobrir (Lourenço et al., 2021). Desta forma, tais conceitos transmitidos, e então considerados como conhecimentos, são aprendidos de forma mecânica, permitindo aos alunos aplicações somente em contextos familiares e conhecidos (Agra, 
2019), limitando-os à compreensão ou instrumentalização para ações autônomas para o enfrentamento de suas realidades (Neves et al., 2019).

A mecanicidade do processo acontece por meio da explicação oral dos professores, transmissores de ideias aos alunos, e estes figuram-se como arquivadores do conhecimento. A troca na relação entre os pares (entre professores e alunos) ocorre com o objetivo de armazenar e reproduzir as ideias transmitidas (Moreira, 2014).

Nesta forma de organização do ensino, os alunos têm a função de cognição passiva, encarados como verdadeiros depósitos de informações que poderão (ou não) lhe serem úteis em seus projetos de vida e os professores renunciam o exercício de técnicas que possam motivar novas informações por meio de descobertas ativas. Na verdade, funcionam como reforços de estabilidades ou mudanças comportamentais desejáveis dos alunos e, por isso, sobrepõem-se hierarquicamente e assumem a centralidade do processo (Nogueira \& Leal, 2015).

Este processo tradicionalista - e, então ultrapassado - de aprendizagem, subsidiada pelo binômio passividade/ reprodutividade de ideias e informações, corrompem o funcionamento e o desenvolvimento da criticidade, da criatividade, da curiosidade e da construção dos alunos, a partir de seus ritmos e necessidades, limitando suas motivações intrínsecas condições sine qua non para a produção dos saberes de temas em questão. Assim, em resposta, têm-se alunos mais apáticos, dependentes do sistema de ensino e dos professores para desenvolver habilidades de cognição e comportamentais, isentando-se da responsabilidade na construção do aprendizado (Honorato, Dias, \& Dias, 2018).

Em síntese, este processo funciona como um sistema de aquisição e manutenção de respostas consideradas como saber e isenção da preocupação em ensinar e motivar os alunos a pensarem e a construírem, de forma ativa, seus conhecimentos (Moreira, 2014).

Carril, Natário e Zoccal (2017) e Augustinho e Vieira (2021) em consenso, afirmam que a educação e o processo de ensino, em todos os níveis e modalidades, sempre estiveram vinculados aos interesses dos governantes e da sociedade como um todo - ou seja, sempre estiveram vinculados aos interesses econômicos, políticos e sociais e, por isso, voltados para disseminação de práticas tradicionalistas para o sustento da reprodução mecanicista das ideias e informações desejáveis a partir do contexto e da contextualização. Para os autores, esta realidade viola o artigo $26^{\circ}$ da Declaração Universal dos Direitos Humanos da Organização das Nações Unidas (ONU), que versa sobre a educação como um direito básico de todos os seres humanos.

A aprendizagem mecânica vem representar o que Paulo Freire concebe como Educação Bancária (Carril, Natário, \& Zoccal, 2017; Augustinho \& Vieira, 2021), ou seja, a concepção crítica à escola tradicionalista que considera os alunos como receptores de informações simplesmente transmitidas pelos professores (Freire, 1987a). Nesta escola, a Educação Bancária (o ensino) assume a missão de instituição informativa e pode-se traduzir como a exposição ou imposição de conhecimentos, sem permissividade ou espaços para discussões e reflexões, afastando-se da missão de instituição formativa (Vasconcelos \& Brito, 2014).

Registra-se que a concepção educacional defendida por Freire $(1987$; 1992; 1995; 1998; 2011) contempla a participação ativa dos alunos, considerados como educandos, para construção de conhecimentos que possam ampliar seus olhares, deixando-os mais críticos e permissivos às reflexões acerca da realidade política e social vigente no contexto em que se encontram inseridos. O protagonismo dos alunos no processo de ensino para construção de uma aprendizagem significativa sempre esteve presente, de forma implícita, no pensamento deste educador.

Este movimento, ao longo dos anos, que busca por mudanças constantes no processo de ensino, é o que Moran (2018) nomeia como educação inovadora, cuja finalidade é a construção de aprendizagens e conhecimentos significativos e úteis para os alunos, então seres humanos e cidadãos que vivem em sociedade. 
Portanto, a partir de um consenso literário, pode-se afirmar que o ensino mecanicista e tradicional e a Educação Bancária sejam inadequados para a atualidade e para o processo da inovação da prática educativa. O cenário é caracterizado pela ascensão dos alunos como construtores de conhecimentos e pelo surgimento de teorias cognitivo-construtivistas da aprendizagem - como por exemplo, a Teoria da Aprendizagem Significativa (TAS) (Moreira, 2013; Nogueira \& Leal, 2015; Distler, 2015; Carril et al., 2017; Honorato, Dias \& Dias, 2018; Agra, 2019; Neves et al., 2019; Augustinho \& Vieira, 2021; Lourenço et al., 2021; PEREIRA et al., 2021).

\subsection{Aprendizagem significativa}

De modo geral, ensinar representa um processo em que um sujeito ajuda outros sujeitos a aprender, de forma intencional; portanto, ensinar representa um processo de aquisição de conhecimento. Contudo, o conhecimento individual não pode ser definido como um objeto concreto, mas como um conjunto de representações mentais que se construíram a partir de um processo dinâmico e interpretativo em que sujeitos do saber estabeleceram junto aos objetos percebidos (Moreira, 2014).

Assim, ensinar e aprender são permeados por mediações e por diferentes representações sobre o mesmo objeto ou sobre o mesmo conhecimento; ou seja, são permeados por representações providas dos professores, alunos, materiais e formas de ensino (Moreira, 2011).

Neste contexto de concepção cognitiva, tem-se a Aprendizagem Significativa conceituada enquanto preocupação em relação ao aprender a pensar e ao aprender a aprender em detrimento à obtenção de comportamentos observáveis; tem-se a responsabilização dos alunos pelo processo pessoal e individual de aprender, com a intenção de ajudá-los com a persistência cognitiva (Moreira \& Masini, 2006).

A partir desta perspectiva, aprender de forma cognitiva pauta-se em dimensões interdependentes: na forma de como o conhecimento é aprendido e esteja disponível aos alunos e; na forma de como os alunos possam incorporar as informações (novos conhecimentos) em suas estruturas individualizadas e já existentes (em seus conhecimentos prévios) (Moreira \& Masini, 2008).

Logo, discussões reflexivas promovidas em salas de aula pelos professores permitem que o processo de ensino esteja centrado nos alunos, com vistas à regulação da construção do conhecimento e da aprendizagem significativa (Moreira \& Masini, 2006; 2008). Os alunos assumem o papel de reclamantes e defensores de suas autonomias, rumando à descoberta e à exploração (Moreira, 2011; 2014).

O conceito de aprendizagem significativa foi proposto por Ausubel (1963; 2003), promotor da Teoria da Assimilação da Aprendizagem e da Retenção Significativa. A referida teoria ocupa-se da abordagem de mecanismos de explicação pautados em processos psicológicos de aprendizagem e em retenções cognitivas humanas. Portanto, afirma-se que a aprendizagem significava acontece a partir de novas informações que se relacionam com aspectos relevantes da estrutura de conhecimentos dos aprendizes e, a partir de então, passam a produzir novos significados/novos conhecimentos.

Distler (2015) e Neves et al. (2017) sintetizam o conceito da aprendizagem significativa de Ausubel enquanto um processo que objetiva a aquisição de novos conhecimentos, tendo o significado como o resultado. Afirmam que o significado (ou seja, o conhecimento) é um fenômeno (produto/resultado) potencial do processo, que se converte em conteúdos cognitivos diferenciados para cada sujeito.

O conhecimento é significativo por definição. Trata-se do produto significativo de um processo psicológico cognitivo (saber) que envolve a interação entre ideias logicamente (culturalmente) significativas, ideias anteriores (ancoradas) relevantes da estrutura cognitiva particular do aprendiz (ou estrutura dos conhecimentos deste) e o mecanismo mental do mesmo para aprender de forma significativa ou para adquirir e reter conhecimentos (Ausubel, 2003). 
Em consenso literário, o conceito de Ausubel pode ser explicado como um processo de aprendizagem: contínuo (considerando sua característica progressiva), pessoal (pois a individualidade do processo o torna como de natureza idiossincrática), intencional (pois, compete aos sujeitos/alunos o estabelecimento de formas de relacionar as novas informações com as ideias relevantes pré-existentes em sua estrutura cognitiva), ativo (pois requer o protagonismo da atividade mental), dinâmico-recursivo (sem linearidade), de interação (de promoção de informações novas com conhecimentos prévios) e interativos (estabelecendo relações critico-reflexivas entre os sujeitos envolvidos no contexto). Por isso esse processo caracterizado, vai gerar um produto provisório (ou um conhecimento particular) produzido em determinado contexto e temporalidade (Carril et al., 2017; Neves et al., 2017; Honorato et al.; Dias \& Dias, 2018; Agra et al., 2019).

Moreira (2013), em um workshop sobre a Teoria da Aprendizagem Significativa, apresentou um mapa conceitual acerca do conceito de Ausubel, representado pela Figura 1.

Figura 1 - Mapa conceitual da Aprendizagem significativa.

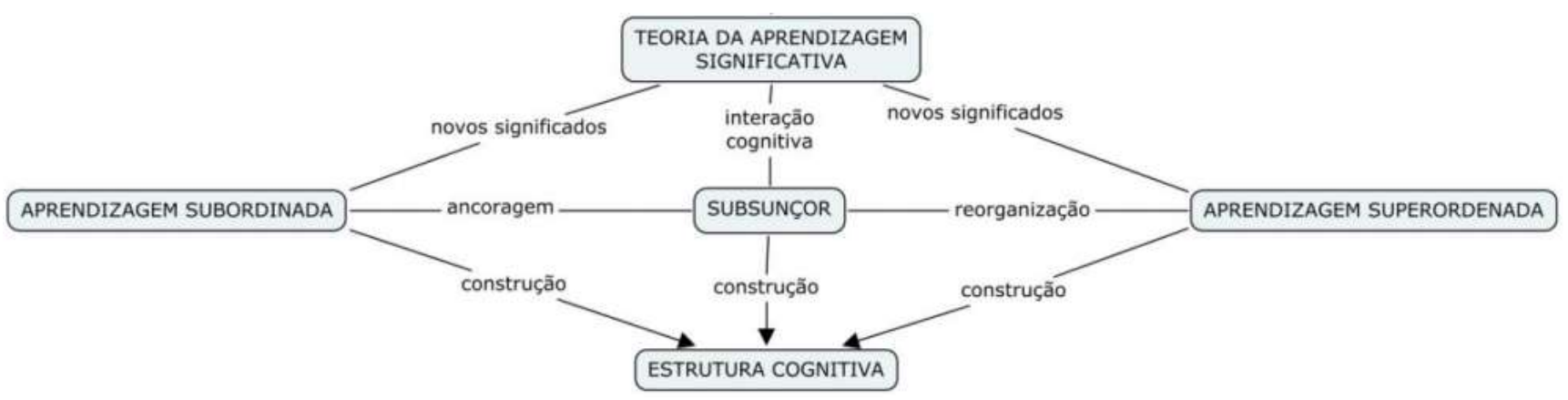

Fonte: Moreira (2013, p.3, adaptado).

Moreira $(2011 ; 2014)$ e Moreira e Masini $(2006 ; 2008)$ destacam que pontos pertinentes na estrutura cognitiva funcionam como ancoradouros para as novas informações e, por isso são chamados de subsunçores. O conhecimento prévio vai servindo, assim, gradativamente para que novos significados possam ser atribuídos às novas informações e, por isso, explica-se que o conhecimento prévio se modifica - ou seja, os subsunçores adquirem novos significados, de forma gradativa e, pois isso se diferenciam e se tornam mais estáveis (significativos).

Considerando a concepção dos mesmo autores e, ainda, interpretando o mapa mental de Moreira (2013), tem-se a assertiva de que o conhecimento prévio é um condicionante para novas aprendizagens, sendo produto da interação das ideias/informações já existentes com as novas e, posteriormente, ambas são modificadas. Para tanto, classifica-se tal processo como único, individual e pessoal.

Já para outros literários, o conhecimento prévio (chamado também de subsunçor ou ideia âncora) é o primeiro antecedente da aprendizagem significativa, definindo-se como um conhecimento específico e relevante que os sujeitos têm na estrutura cognitiva, com a incumbência de produção de novos significados aos conhecimentos apresentados/descobertos/aprendidos pelos mesmos sujeitos (Carril et al., 2017; Neves et al., 2017; Honorato et al, 2018; Agra et al., 2019). Além disso, a ação de atribuir significados aos novos conhecimentos apresentados/descobertos/aprendidos vai depender da existência (ou não) de conhecimentos prévios (ou subsunçores) nas estrutura de cognição de cada um dos sujeitos. Por isso, é mister dar destaque ao que Ausubel concebe enquanto estrutura cognitiva - ao conteúdo total e organizado de ideias e conhecimentos prévios de cada sujeito (Carril et al, 2017; Neves et al., 2017; Honorato et al., 2018; Agra et al., 2019).

Afirma-se, o funcionamento de um organizador prévio; ou seja, funcionamento de uma modalidade instrucional, caracterizada pela abstração, generalização e pela inclusividade dos materiais de aprendizagem, com a finalidade ou objetivo de ajudar os sujeitos (aprendentes) na percepção das relações entre novos conhecimentos e subsunçores já inerentes na 
estrutura cognitiva. O organizador prévio serve para facilitar aprendizagens, considerando que assume a função de uma ponte de cognição (Honorato et al., 2018; Agra et al., 2019; Lourenço et al., 2021; Augustinho \& Vieira, 2021).

Moreira $(2011 ; 2014)$ e Moreira e Masini $(2006 ; 2008)$ asseguram que, para que a aprendizagem se torne efetivamente significativa, os sujeitos aprendizes devem ter a intenção de relacionar os novos conhecimentos de forma lógica/não arbitrária e não literal/substantiva aos seus conhecimentos prévios. Devem estar dispostos a relacionar os novos conhecimentos com os conhecimentos prévios, para que tornem-se elaborados/enriquecidos/estáveis, para que possam adquirir significados e serem integrados à estrutura cognitiva. A perspectiva da aprendizagem significativa de Ausubel, a partir da sua teoria relacionada, vem representar uma estratégia auspiciosa e encorajadora para situações formais de ensino e, por isso, representa uma interação não arbitrária e não literal de conhecimentos prévios com os novos (Augustinho \& Vieira, 2021; Lourenço et al., 2021). Por meio de sucessivas interações, determinados subsunçores, de forma progressiva, adquirem novos significados, tornam-se enriquecidos, refinados e, por isso diferenciados, sendo capazes de servir de âncoras para novas aprendizagens significativas (Carril et al., 2017; Neves et al., 2017; Honorato \& Dias; Dias, 2018; Agra et al., 2019).

Retomando Moreira (2013), um novo mapa conceitual da Aprendizagem significativa de Ausubel, mais elaborado e detalhado, recepcionado pela Figura 2, explana melhor as afirmativas estabelecidas até aqui.

Figura 2 - Mapa conceitual da Aprendizagem significativa de Ausubel.

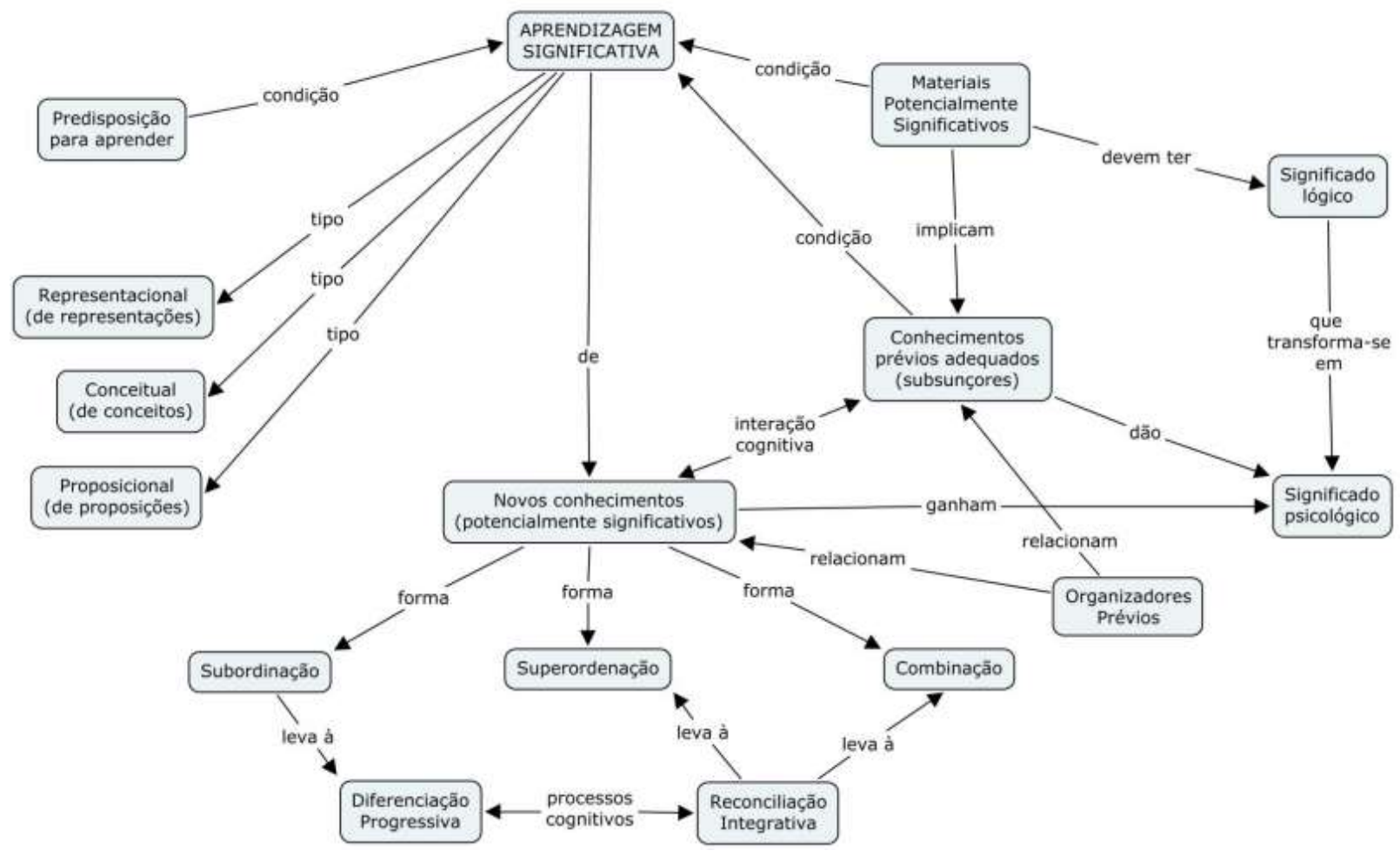

Fonte: Moreira (2013, p.5).

Uma reflexão da Teoria de Ausubel é que, de todos os fatores influenciadores da aprendizagem, o mais relevante é o que os alunos previamente sabem e, por isso, representam o ponto de partida (Nogueira \& Leal, 2015; Carril et al., 2017; Agra et al., 2019). Assim, considera-se que a ação de desvendar o que os alunos já sabem representa muito mais do que identificar suas representações/conceitos/ideias, haja vista a necessidade de considerar a totalidade dos seres culturais/sociais em suas manifestações/linguagens corporais/afetivas/cognitivas. E, neste contexto, competem aos professores a abertura para que os 
alunos revelem suas expectativas vivenciadas, de suas experiências e condições de existência, não somente considerando o aspecto intelectual desta clientela (Carril et al., 2017; Neves et al., 2017; Honorato et al., 2018; Agra et al., 2019).

Contudo, uma inquietação se faz emergente: o que se pretende atingir com a promoção da aprendizagem significativa? De acordo com Augustinho e Vieira (2021), a aprendizagem significativa preconiza a participação ativa dos alunos e, para tanto, cabe aos professores assumirem um papel concomitante com este postulado. Como bem coloca Moran (2018), demandase que a escola reconheça a transitoriedade das informações, sendo de competência dos professores a adesão a um novo papel, que esteja adequado ao contexto: a mediação da aprendizagem.

De acordo com Anastasiou (2015), compete aos professores, na atualidade, a criação de ambientes propícios e propensos para o desenvolvimento de seus alunos, em um processo de colaboração mútua. Para tanto, Pereira et al. (2021) acreditam que os professores precisam empregar metodologias adequadas, buscando a participação ativa de seus alunos, enquanto sujeitos de suas aprendizagens, para que a aprendizagem significativa aconteça; para que a aprendizagem ocorra de uma forma diferenciada, com reflexos para a vida destes alunos, sendo permeada por processos críticos e reflexivos, para construção e constante reconstrução de cidadãos e seres sociais que interagem com o meio. Augustinho e Vieira (2021),

Lourenço, Alves e Silva (2021) e Pereira et al. (2021), afirmam ser essencial acatar os alunos como sujeitos que possuem conhecimentos prévios, associados às experiências e aos saberes que os construíram. Justificam, com base em Paulo Freire, que este saber pautado na autonomia do educando se faz imprescindível à prática educativa. E, em relação à prática educativa, os autores asseguram que os professores devem fazer uso das experiências concretas dos alunos para a base de seus processos de aprendizagem, como uma forma de pedagogia orientada para os alunos enquanto sujeitos-ativos em busca da construção de significados. Por isso, defendem o trabalho com as metodologias ativas (com descobertas, problematizações e elaboração de ações) para a promoção da aprendizagem significativa em detrimento a aprendizagem por recepção.

\subsection{Metodologias ativas e aprendizagem significativa}

O enunciado 'ensino e aprendizagem' deve ser compreendido de forma interdependente, no qual o processo de ensinar esteja atrelado ao processo de aprender. Quando os termos são compreendidos dissociadamente, conota-se uma separação das ações e uma independência dos processos, levando à crença de que compete aos professores ensinar/transmitir conteúdos e aos alunos aprender/memorizar e armazenar conteúdos (Anastasiou, 2015). Ao enunciar 'ensino e aprendizagem', entende-se que os objetivos e métodos de ensino centram-se no favorecimento da aprendizagem, superando a fixação de conteúdos e assumindo o papel de desenvolvimento da cognição e, por isso, o enunciado é sempre acompanhado de ações ativas ou condicionantes da aprendizagem, tais como: entender, indagar, assimilar, comparar, compreender, criticar, problematizar, buscar soluções. Assim, os condicionantes da aprendizagem demandar por inovação no ensino e adesão às novas metodologias, denominadas como ativas (Anastasiou, 2015; Pereira et al., 2021).

Para Augustinho e Vieira (2021), a educação e as escolas devem considerar o mundo em plena transformação, subsidiada pela revolução tecnológica e digital, com descobertas científicas diversas e, consequentemente, mudanças sociais. Por isso, o ensino e a aprendizagem devem estar consoantes à nova realidade, operando por propostas pedagógicas adequadas para suprir às demandas socais e as necessidades individuais. A própria Base Nacional Comum Curricular (BNCC) preconiza a aprendizagem com base em competências, prezando por uma educação afirmativa em valores e, para tanto, estimula ações que corroborem com a transformação da sociedade (Brasil, 2017).

E, para o desenvolvimento das competências preconizadas na referida base curricular, um consenso literário enaltece as metodologias ativas, considerando que estas assumam um papel relevante para o processo de 'ensino e aprendizagem', haja vista o seu direcionamento para o estímulo da autonomia e da participação ativa dos alunos na construção de seus 
conhecimentos (Diesel \& Baldez, 2017; Neves \& Rodrigues, 2017; Mota \& Werner, 2018; Augustinho \& Vieira, 2021; Pereira et al., 2021; Lourenço \& Alves, 2021).

$\mathrm{Na}$ verdade, é vasto o número de estudos acadêmico-científicos e teóricos ativos com o objetivo de promoção de avaliações sobre o melhor meio para se aprender. Dentre eles, uma teoria relevante e consonante com a Teoria da Aprendizagem Significativa é a da Pirâmide da Aprendizagem do psiquiatra americano Willian Glasser. O psiquiatra, para promoção de sua teoria, embasou-se em 'The Psychology of Meaningful Verbal Learning' (A Psicologia Verbal da Aprendizagem Significativa) - uma obra de Ausubel, publicada em 1963 (Carotenuto \& Pereira, 2020).

A Teoria da Pirâmide da Aprendizagem de William Glasser revela a existência de diferentes níveis de aprendizagem (percentuais de aprendizagem realmente significativa), a partir de cada procedimento (ou a partir de cada um dos condicionantes da aprendizagem) e das formas ativas de aprender que cada um destes níveis promove (Carotenuto \& Pereira, 2020), como mostra a Figura 3.

Figura 3 - Pirâmide de aprendizagem de William Glasser.

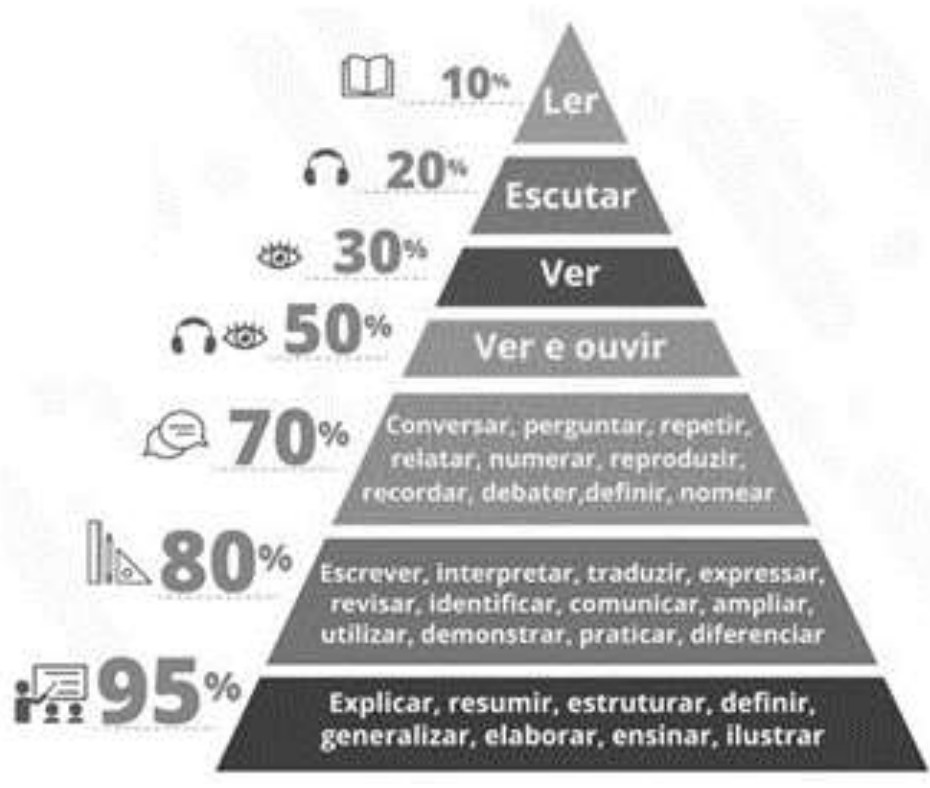

Fonte: Carotenuto e Pereira (2020, p.1).

O teórico William Glasser afirma que o ensino por meio da memorização não se faz mais adequado, assegurando que, ao término de cada aula, os conteúdos dispostos a serem memorizados já são esquecidos por grande parte dos alunos. Sua teoria defende uma aprendizagem ativa como forma exitosa para os alunos e garante que as escolas que adotam metodologias ativas, em todos os seus níveis de ensino, aumentam a aprendizagem de seus alunos em pelo menos 95\% (Carotenuto \& Pereira, 2020).

Por tal constatação, compete ao ambiente educacional e aos sujeitos nele inseridos, o cumprimento da promoção da aprendizagem por meio do desenvolvimento de competências essenciais para que os educandos atuem no século XXI, desvendando conhecimentos teórico-práticos e, principalmente, incluindo práticas inovadoras (e, então, ativas) em suas rotinas de aprendizagem (Augustinho \& Vieira, 2021; Pereira et al., 2021; Lourenço \& Alves, 2021).

Muitos são os benefícios trazidos aos estudantes com a adoção das metodologias ativas de ensino, dentre eles: melhoria no engajamento/motivação da aprendizagem; segurança em protagonizar a aprendizagem; desenvolvimento de habilidades e na resolução de problemas; promoção da autoconfiança e exercício da criticidade e; desenvolvimento da autonomia (Diesel \& Baldez, 2017). 
Pereira et al. (2021) trouxeram, em seus estudos, um mapa conceitual para a prática do ensino por meio de metodologia ativa, conforme Figura 4.

Figura 4 - Mapa conceitual sobre metodologias ativas.

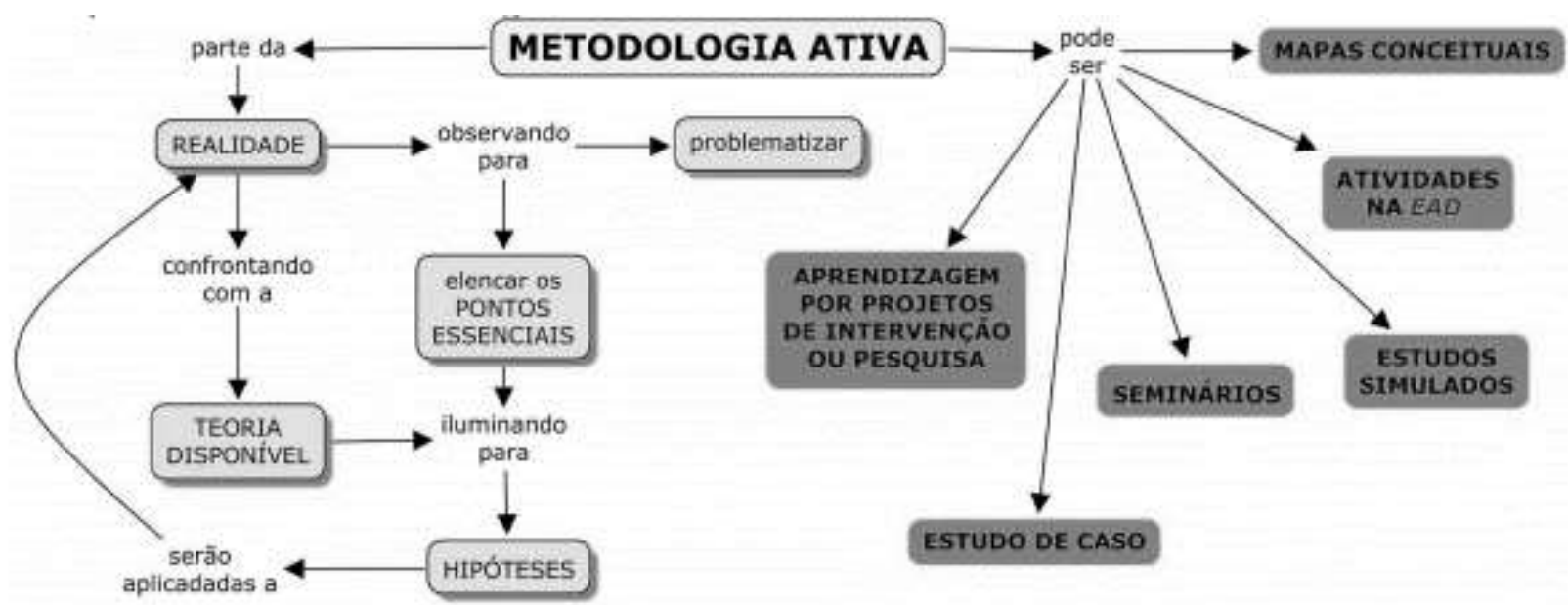

Fonte: Pereira et al. (2021. p.17).

Augustinho e Vieira (2021) exemplificam algumas atividades pertencentes às metodologias ativas: Aula/Classe Invertida; Aprendizagem Baseada em Problemas; Aprendizagem Baseada em Projetos; Aprendizagem Baseada em Jogos; Instruções por pares (Peer Instruction); Ensino sob medida (Just-In-Time Teaching), Aprendizagem Baseada em Times; Método de Caso; Simulações; Ensino por Investigações.

Para que os professores classifiquem ou identifiquem uma metodologia como viável ou apropriada ao processo de 'ensino e aprendizagem', precisam estudar e conhecer seus alunos, compreendendo como os mesmos aprendem, em que universo estão inseridos (suas realidades e contextos) e seus níveis de interesse, para que suas expectativas possam ser alcançadas (Neves \& Rodrigues, 2017; Bossi \& Schimiguel, 2020).

Entretanto, é imprescindível considerar que a aplicação das metodologias ativas para obtenção dos benefícios aos alunos e êxito do processo de aprendizagem pode trazer, inicialmente, desafios e dificuldades, pois nem todos os alunos aceitam a proposta ou os próprios professores recusam o método de trabalho, dando preferência e acreditando que o método tradicional é o mais fácil e o que exige menos esforço, de ambas as partes (Mota \& Werner, 2018). Na verdade, tanto para os alunos quanto para os professores, a adesão às metodologias ativas de ensino demanda por planejamento, participação, dinamicidade e engajamento e, por isso, a princípio, aparenta ser mais trabalhoso (Lourenço \& Alves, 2021). Desta forma, é oportuna a promoção de discussões acerca das tendências adequadas e apropriadas ao processo de 'ensino e aprendizagem', na tentativa de desmistificar e desbancar a prática tradicionalista que ainda existe nas salas de aula, marcada pela passividade dos alunos e pela acomodação dos professores. Frente ao todo, as metodologias ativas prontificam-se como um processo de mudança, com estratégias de ensino que buscam a participação dos alunos e pelo protagonismo caracterizado, associadas à mediação exercida pelos professores, tendo como produto a promoção de uma aprendizagem significativa (Augustinho \& Vieira, 2021; Pereira et al., 2021; Lourenço \& Alves, 2021).

Afirma-se, então, que o contexto reflexivo seja parceiro das metodologias ativas enquanto suporte para a promoção da aprendizagem significativa, justificando-se na culminância da aprendizagem por meio do protagonismo exercido em busca da transformação da realidade. E, para que transformações aconteçam, novas competências e habilidades devem ser colocadas em prática para a busca da educação inovadora, que contempla o desenvolvimento sustentável e regional e questões sociais, 
culturais, ambientais e econômicas, além das questões políticas, com o exercício de tomadas de decisões participativas e responsáveis (Augustinho \& Vieira, 2021; Pereira et al., 2021; Lourenço \& Alves, 2021).

Moran (2018) denomina a aprendizagem significativa como aprendizagem mais profunda, em promoção à uma educação inovadora, que potencializa o protagonismo dos alunos e a personalização do ensino, pois a educação pauta-se em problemas reais, em desafios relevantes, com resolução a partir da aplicação de jogos, de leitura de mundo e de projetos pessoais de vida ou coletivos. O contexto demanda, então, por mudanças na configuração curricular, na participação dos professores em assumir o papel de mediação, na organização das atividades didáticas e na reorganização do tempo e dos espaços disponíveis para a promoção da educação. Para o autor, a adesão às metodologias ativas contempla e comporta tal mudança curricular, considerando que possibilita o desenvolvimento de habilidades e conhecimentos por meio de estímulos, descobertas, interatividade, intervenção, participação e bidirecionalidade.

Portanto, o protagonismo se faz condição e elemento principal para uma nova forma e visão do processo 'ensino e aprendizagem', cujo foco passa a ser dialógico, reconhecendo e tomando consciência da demanda dos sujeitos para a transformação desejada. Nessa perspectiva, é necessário pensar os sujeitos aprendentes como educandos, que possuem conhecimentos prévios, saberes e experiências. Por isso, afirma-se que as metodologias ativas, fundamentadas no protagonismo, além de método para os professores, figuram-se como forma de propagação da aprendizagem significativa (Augustinho \& Vieira, 2021; Pereira et al., 2021; Lourenço \& Alves, 2021).

A aprendizagem significativa pauta-se no dinamismo, nos saberes dos alunos como o ponto de partida e, também, o ponto de chegada. Resume-se na construção e na reconstrução de conhecimentos e significados, que tornarão instrumentos para ações e reações dos seres humanos na realidade e no contexto em que encontram-se inseridos (Carril et al., 2017). Desta forma, as metodologias ativas constituem-se caminhos para a prática educativa dinâmica, instigadora e significativa (Pereira $e t$ al., 2021).

Conclui-se, então, que as metodologias ativas de ensino e a teoria da aprendizagem significativa sejam convergentes, considerando a prioridade de deslocamento do protagonismo do processo de ensino e aprendizagem para os alunos, valorizando seus conhecimentos prévios, considerando suas inquietações (problematizações) para a descoberta daquilo que desejam saber/conhecer, de uma forma crítica e reflexiva - ou seja, duradoura e significativa (Diesel \& Baldez, 2017; Neves \& Rodrigues, 2017; Mota \& Werner, 2018; Augustinho \& Vieira, 2021; Pereira et al., 2021; Lourenço \& Alves, 2021).

\subsection{Design Thinking}

O design, segundo Santos et al. (2017, p. 06), é um termo conceituado internacionalmente pelo International Council of Societies of Industrial Design (ICSID, 2011), sendo compreendido "[...] como uma atividade cerne da inovação e das mudanças culturais e econômicas" e que, nesse sentido, não se restringe ao ambiente empresarial.

De acordo com Oliveira (2014), a base para o design thinking é a (1) empatia, (2) colaboração e (3) experimentação das ideias. Logo, de acordo com as diretrizes desta metodologia, é possível por meio de equipes colaborativas que conversam entre si, obter uma melhor compreensão acerca de uma situação problema, identificar e experimentar ideias abstratas na realidade, para se identificar a melhor solução para a situação em questão. Sendo assim, por meio da Empatia que deve ser priorizada em uma equipe de professores, é possível desenvolver metodologias de ensino inovadoras a partir da análise e combinação dos conhecimentos e experiências particulares dos docentes relacionados com a situação problema. Esta combinação dará origem à um conhecimento no nível coletivo mais aprimorado. A Empatia também direciona o educador a se colocar na posição dos seus alunos para que neste processo as necessidades dos referidos sejam consideradas (Brown \& Wyaat, 2010). 
Este posicionamento é reforçado por meio da Colaboração, que determina que os produtos devem ser desenvolvidos com os clientes e não para os clientes, ou seja, no âmbito educacional as necessidades, percepções e sugestões dos alunos precisam ser consideradas no momento de se desenvolver novas metodologias de ensino. Por fim, na Experimentação, os educadores irão explicitar as ideias de solução por meio de protótipos ou outros artefatos, para seja possível avaliar os pontos fortes e fracos com o intuito de validar a proposta (metodologia de ensino) ou realizar os ajustes necessários (Oliveira, 2014).

Compreendendo que a educação busca desenvolver competências, habilidades e atitudes que sejam úteis aos alunos em suas vidas, percebe-se que o Design Thinking pode ser aplicado no âmbito educacional com esta finalidade, pois esta metodologia busca direcionar equipes no processo de desenvolvimento de soluções inovadoras para problemas reais, bem como, considera as necessidades e expectativas dos indivíduos que irão fazer uso destas soluções. A aplicação do Design Thinking para o desenvolvimento de metodologias de ensino ativas que favoreçam a aprendizagem significativa se dá por meio das seguintes fases (Oliveira, 2014; Santos et al., 2017): (1) descoberta, (2) interpretação, (3) ideação (4) experimentação e (5) evolução.

Na Descoberta busca-se compreender o problema que necessita ser solucionado. Nesta etapa, para desenvolver a metodologia de ensino, os educadores de uma mesma disciplina irão se reunir para identificar e descrever: (1) os conteúdos da disciplina que serão abordados; (2) os objetivos de aprendizagem da disciplina; (3) as dificuldades de professores e alunos no processo de ensino-aprendizagem destes conteúdos de modo significativo. Na Interpretação, os educadores irão compartilhar as suas percepções e experiências acerca das dificuldades de professores e alunos no processo de ensino-aprendizagem dos conteúdos da disciplina, com intuito de identificar as possíveis metodologias de ensino que poderiam ser utilizadas para se promover um aprendizado significativo. Neste momento, recomenda-se aos educadores que busquem estabelecer novas metodologias para despertar um maior interesse pelo processo de ensino-aprendizagem, em vez de fazer uso somente das tradicionais, já conhecidas por muitos alunos. Acrescenta-se que é possível selecionar uma metodologia tradicional e inserir elementos inovadores. Na Ideação, a proposta de solução mais viável (a metodologia de ensino selecionada) é explicitada em um documento físico ou digital por meio de texto, fluxogramas, imagens, entre outros recursos identificados pelo professor. Este documento subsidiará a sua aplicação pelo docente e poderá até auxiliar os alunos a compreenderem a proposta. Acrescenta-se que a proposta pode ser explicitada também por meio de um artefato, como por exemplo, um jogo educativo digital (software). Na Experimentação, ocorrerá a aplicação da metodologia de ensino pelos professores que fazem parte da equipe de desenvolvimento para validá-la. Cada educador irá identificar e registrar as potencialidades e limitações da metodologia de ensino a partir da sua primeira experiência ao aplicá-la. Os educadores se reunirão para compartilhar essas informações e realizar os ajustes necessários, se for o caso. Por fim, na Evolução, se faz o acompanhamento e registro do desempenho da metodologia no processo de ensino-aprendizagem visando a melhoria contínua. Os educadores poderão, por exemplo, se reunir semestralmente para compartilhar as suas percepções acerca do desempenho esperado e obtido para aprimorar a metodologia de ensino ao longo do tempo (Brown \& Wyaat, 2010; Viana, 2012; Oliveira, 2014).

É importante ressaltar que, visando melhores resultados no processo de ensino-aprendizagem, os professores que ministram a disciplina poderão incluir na equipe de desenvolvimento outros colaboradores importantes da Unidade Escolar como Coordenador Pedagógico, Supervisor Pedagógico, entre outros. O Design Thinking permite identificar as necessidades que não estão sendo atendidas no processo de ensino-aprendizagem, além de permitir a construção de soluções com base na união e redução de erros por meio da experimentação. O seu uso na educação reforça o quanto, em um ambiente escolar, todos os elementos precisam estar conectados, desde sociedade, família, professores e alunos (Viana, 2012; Santos et al., 2017). 


\section{Metodologia}

Para se atender aos objetivos deste estudo, optou-se por realizar uma pesquisa do tipo exploratória e descritiva e de abordagem qualitativa, para se obter um entendimento aprofundado do contexto de uma determinada Instituição de Educação Básica por meio da análise das percepções dos seus colaboradores que subsidiaram o desenvolvimento de um curso de qualificação profissional para a aplicação e desenvolvimento de metodologias ativas que favoreçam a aprendizagem significativa por meio do Design Thinking. Esta etapa foi fundamental para se desenvolver um curso que contemplasse a realidade de Instituições de Educação Básica. Esta pesquisa pode ser caracterizada também como bibliográfica pois a fundamentação teórica do referido curso foi desenvolvida por meio da análise de livros e artigos científicos que tratam sobre o assunto (Godoy, 1995).

A Instituição de Educação Básica pública que foi investigada no período de janeiro/2021 à julho/2021, localiza-se na região Sul de Minas Gerais e possui em média 1400 alunos, oferecendo o Ensino Fundamental I e II, Ensino Médio, EJA. Em um primeiro momento, realizou-se entrevistas com os seguintes profissionais desta escola: Diretor, Supervisor Pedagógico e quatro (04) Docentes, sendo um (01) professor de educação física, um (01) professor de Arte, um (01) professor de português; e um (01) professor do primeiro ano do Ensino Fundamental I. Nestas entrevistas buscou-se compreender a concepção destes profissionais acerca de aprendizagem significativa, metodologias ativas e se a escola já havia oferecido formações continuadas sobre esta temática (Godoy,1995). Após o desenvolvimento e efetivação deste curso de qualificação profissional, alguns dos profissionais de educação que vivenciaram o curso em questão foram entrevistados com o intuito de se obter evidências acerca da sua efetividade quanto ao seu propósito formativo. Os relatos obtidos foram transcritos e analisados por meio da técnica de codificação que trata-se da identificação de registros de uma ou mais passagens de texto que exemplificam a mesma ideia teórica e descritiva. Geralmente, várias passagens são identificadas e então relacionadas com um nome para a ideia, ou seja, com um código. Portanto, baseando-se em todo o texto, os elementos que se referem à mesma ideia ou exemplificam a mesma ideia são codificados com o mesmo nome. (Gibbs, 2009).

Acrescenta-se que esta pesquisa foi aprovada pelo Comitê de Ética sob número de parecer 4.662.846. Acrescenta-se ainda, que durante o desenvolvimento do material didático deste curso considerou-se os princípios de design instrucional com o objetivo de abordar os conteúdos do modo claro, prático e significativo durante o processo de ensino e aprendizagem.

\section{Resultados e discussão}

\subsection{Realidade da Instituição de Educação Básica investigada}

Nas primeiras entrevistas realizadas que buscaram conhecer a realidade da escola investigada, constatou-se que nunca ocorreu uma formação continuada sobre metodologias de ensino ativas. De acordo com o Supervisor, não se identificou uma necessidade que justificasse a realização de tal formação. Já, um dos docentes entrevistados relatou que formações sobre esta temática precisam ocorrer, inclusive, esta necessidade evidencia-se durantes as discussões que acontecem nas reuniões de colegiado. Ainda, segundo este docente, o que dificulta a realização de formações continuadas é a falta de autonomia das escolas públicas e o processo burocrático que precisa ser seguido para a efetivação. Cita-se a aprovação de órgãos superiores para a realização das capacitações como as Secretárias de Educação.

Buscou-se averiguar também, segundo a concepção dos entrevistados, se as metodologias ativas podem ocasionar melhores resultados no processo de ensino e aprendizagem em relação às tradicionais. De acordo com os relatos obtidos, estas metodologias tornam o aluno protagonista no processo de ensino e aprendizagem. Sendo assim, o educando poderá refletir, questionar e selecionar experiências que possibilitem um aprendizado significado para a sua realidade. Ressalta-se ainda, conforme relatos, que estas metodologias possibilitam apresentar cenários que se relacionam com a realidade do aluno e com o seu conhecimento prévio. 
Quanto às dificuldades em se aplicar novas metodologias de ensino, de acordo com os entrevistados, destaca-se a ausência dos recursos necessários para se aplicar metodologias diferenciadas nas escola de Educação Básica públicas, o que não ocorreria nas privadas. Identificou-se que esta diferenciação ficou ainda mais evidente no período de Pandemia, já que a interlocução remota iniciou, primeiramente, nas escolas privadas. Segundo os entrevistados, as escolas públicas não dispunham de recursos tecnológicos e muitos professores não possuíam o conhecimento necessário para utilizá-los. Acrescenta-se que está diferenciação de realidade se estende aos alunos das instituições públicas, já que muitos não conseguiram acompanhar as aulas no período de ensino remoto por não possuírem computadores, tablets, celulares e uma boa conexão de internet.

\subsection{Sobre o curso de qualificação profissional}

Elaborado com uma linguagem prática, clara e objetiva, o curso de qualificação profissional para o desenvolvimento de metodologias de ensino ativas por meio do Design Thinking está organizado em três módulos que propõem exercícios de aprendizagem para possibilitar a aquisição de conhecimento prático. Neste produto técnico/tecnológico caracterizado como um guia de estudos de um curso de qualificação profissional é evidenciado a importância de viabilizar uma aprendizagem significativa no processo de ensino e aprendizagem para que os alunos possam adquirir as competências, habilidades e atitudes requeridas pelo currículo da Educação Básica e mundo de trabalho.

Buscou-se, também, descrever aos participantes como as metodologias ativas podem favorecer a aprendizagem significativa e, por fim, foi demonstrada a relevância do Design Thinking para o desenvolvimento de novas metodologias de ensino ativas que favoreçam a aprendizagem significativa. O Quadro 1 apresenta os objetivos de aprendizagem e os conteúdos abordados em cada módulo do curso em questão.

Quadro 1: Objetivos de aprendizagem e conteúdos do curso de qualificação profissional desenvolvido.

\begin{tabular}{|c|c|}
\hline \multicolumn{2}{|c|}{$\begin{array}{lcclllll}\text { CURSO DE } & \text { QUALIFICAÇÃO } & \text { PROFISSIONAL } & \text { PARA } & \text { O } & \text { DESENVOLVIMENTO } & \text { DE } \\
\text { METODOLOGIAS ATIVAS POR } & & & & & \end{array}$} \\
\hline $\begin{array}{l}\text { OBJETIVOS } \\
\text { DEAPRENDIZAGEM }\end{array}$ & $\begin{array}{l}\checkmark \text { Possibilitar o entendimento acerca da importância de se aplicar metodologias } \\
\text { ativas que possibilitem a aprendizagem significativa. } \\
\checkmark \text { Possibilitar o entendimento sobre o modo de aplicação das principais } \\
\text { metodologias ativas que favorecem a aprendizagem significativa. } \\
\checkmark \text { Possibilitar o entendimento acerca do uso do Design Thinking para o } \\
\text { desenvolvimento de metodologias ativas que atendam às necessidades de } \\
\text { docentes e discentes }\end{array}$ \\
\hline MODULO I & A importância de viabilizar uma aprendizagem significativa na Educação Básica. \\
\hline MODULO II & $\begin{array}{l}\text { Como as metodologias ativas podem favorecer a aprendizagem significativa na } \\
\text { Educação Básica? }\end{array}$ \\
\hline MODULO III & $\begin{array}{l}\text { O uso do Design Thinking para o desenvolvimento de metodologias de ensino } \\
\text { ativas que favoreçam a aprendizagem significativa. }\end{array}$ \\
\hline
\end{tabular}

Fonte: Elaborado pelos autores.

O Módulo I "A importância de viabilizar uma aprendizagem significativa na Educação Básica”, apresentou o conceito de aprendizagem significativa com base na definição de Ausubel (2001). O objetivo foi demonstrar que a teoria de Ausubel (2001) considera o conhecimento prévio do aluno ou a bagagem de conhecimentos que traz consigo para escola e ao relacionar o que se está aprendendo com a realidade conhecida, representada por sua estrutura cognitiva, o aluno vê sentido em se aprender determinados conteúdos. Discorreu-se também sobre a importância de os educadores identificarem e analisarem as 
dificuldades dos seus alunos para tornar a aprendizagem mais significativa (Neves et al., 2017; Honorato et a.,2018; Agra et al., 2019). Ao final, foi proposto um exercício de aprendizagem que consistiu na descrição dos principais obstáculos para se promover a aprendizagem significativa dos conteúdos das disciplinas ministradas pelos participantes, caso houvesse.

O Módulo II "Como as metodologias ativas podem favorecer a aprendizagem significativa na Educação Básica?", apresentou metodologias ativas que poderão ser utilizadas para inovar a forma de transmitir os conteúdos das disciplinas aos alunos, além de situações que demonstram a aplicação em sala de aula. Cita-se como exemplo: aprendizagem baseada em problemas; aprendizagem baseada em projetos; gamificação; sala de aula invertida; peer-instruction; dramatização; quiz; storytelling; entre outras. Buscou-se evidenciar ao educador a necessidade de inovar a sua prática docente para que o referido deixe de ser um transmissor de conhecimento para se tornar um mediador e um facilitador, favorecendo o aprendizado significativo. Ao final, foi proposto um exercício de aprendizagem no sentido de provocar os educadores a identificarem dentre as metodologias ativas apresentadas, aquelas que poderiam atender às necessidades de suas disciplinas (Anastasiou, 2015; Diesel \& Baldez, 2017; Pereira et al., 2021; Lourenço \& Alves, 2021).

O Módulo III "O uso do Design Thinking para o desenvolvimento de metodologias de ensino ativas que favoreçam a aprendizagem significativa", buscou sensibilizar os educadores acerca da importância de desenvolver novas metodologias de ensino por meio do Design Thinking. Discorre-se sobre cada uma das etapas do Design Thinking, sendo: (1) descoberta, (2) interpretação, (3) Ideação (4) experimentação e (5) ideação (Viana, 2012; Oliveira, 2014; Santos et al., 2017).

Ao final, foi proposto um exercício em equipe que solicitou o desenvolvimento de uma metodologia de ensino inovadora por meio do Design Thinking para alguma disciplina.

\subsection{Evidências acerca da efetividade do curso de qualificação profissional desenvolvido}

Com o intuito de obter evidências acerca da efetividade do curso de qualificação docente desenvolvido quanto ao seu propósito formativo, entrevistou-se alguns dos profissionais da escola investigada que vivenciaram o curso em questão que ocorreu em agosto de 2021 por meio do Google Meet. Estes profissionais também fizeram uso do Google Forms para desenvolver os exercícios de aprendizagem, principalmente o exercício do Módulo III que necessita ser efetivado em equipe. Seguem alguns relatos:

O diretor, parte integrante da equipe gestora da escola e que possui experiência com o uso de metodologias ativas, apresentou o seguinte parecer:

Material bem apresentado, sucinto e com muitas referências de autores que proporciona segurança em sua aplicação no ambiente escolar, trazendo diversas propostas exemplificadas de metodologias ativas. Diante do exposto, em momento oportuno, me sinto seguro para aplicação do material em sala de aula (DIRETOR).

Quanto a sua proposta e exercícios de aprendizagem, estes professores apresentarem os seguintes pareceres:

Achei o material muito interessante, bem explicado, bem-organizado. A proposta de pensarmos atividades que insiram tal metodologia, contribui para a aproximação do docente. É a relação da prática e teoria, do aprendizado teórico e sua implementação na prática (PROFESSOR B).

Acredito que pensar as metodologias como algo possível, sobretudo através da parceria e da união de mais pares, proporciona um novo olhar para a educação e sua prática. É como se aquele ideal de mudança que, em muitos casos, motivaram à carreira docente, e que devido a diversos fatores, foram sendo desencorajados, desestimulados $e$ trocados pela realização de atividades burocráticas, se tornasse possível novamente. A colaboração, o pensar e refletir o novo, e, sobretudo, acreditar que a mudança é possível, são estruturas essenciais para um novo modelo de educação que nós, como professores, vamos ter orgulho e prazer de trabalhar (PROFESSOR D). 
Gostei do conteúdo apresentado, já tinha algumas breves noções sobre o tema abordado e pude conhecer mais e me aprofundar um pouco mais sobre a proposta. creio que pode ser de grande valia aplicado em um curso de capacitação para aprendizagem e reciclagem de professores, pois precisamos estar em constante evolução de aprendizado, seguindo o ciclo de toda sociedade (PROFESSOR A).

Me agrada muito o conceito sobre a aprendizagem significativa, onde se aproveita os conhecimentos prévios do aluno, pois partimos de um ponto onde o aluno possui algum conteúdo próprio, e a partir disso ampliamos e atualizamos o seu conhecimento. Creio ser um método que quando bem aplicado conseguimos alcançar até mesmo alunos que nos inspiram mais desafios para com o aprendizado em si, fazendo com que o aluno se sinta parte do processo de construção do conhecimento e não somente um mero espectador (SUPERVISOR).

Portanto, acredita-se que o curso cumpre o seu propósito de contribuir para o desenvolvimento das competências, habilidades e atitudes que possibilitem aos educadores utilizar e desenvolver metodologias de ensino ativas que favoreçam a aprendizagem significativa.

\section{Considerações Finais}

Ao final desta investigação, foi possível atender o objetivo principal deste estudo que consistiu em produzir um curso de qualificação profissional que possibilite aos educadores da Educação Básica compreender como aplicar e desenvolver metodologias de ensino ativas que favoreçam a aprendizagem significativa, por meio do Design Thinking.

Neste âmbito, destaca-se a atividade que foi desenvolvida em equipe durante o curso, do Módulo III, denominada "Poesia em todo canto" e que envolveu as disciplinas Português, Artes, Filosofia e Educação Física. A referida possui o propósito de ajudar alunos e professores a interagirem, se conhecerem, criarem e inovarem para atingir o objetivo de tornar ativa a arte poética em vários segmentos na escola. A ideia partiu do pressuposto de que alunos que convivem com poesia conseguem pensar melhor sobre o mundo em que vivem e criar soluções que beneficiem a sociedade, colocando-se como protagonistas nele. Além destes objetivos, esta atividade busca contribuir para o desenvolvimento de capacidades cognitivas, físicas e perceptivas por meio da utilização das seguintes metodologias ativas que foram adaptadas, conforme a proposta estabelecida pelos professores e de acordo com as orientações do guia de estudos: sala de aula invertida; dramatização; memes.

Em suma, no momento em que se fará uso da Sala de Aula Invertida, o professor de Português pedirá aos alunos para pesquisarem e desenvolverem uma aula sobre poesia, por meio da busca de conceitos, poetas, biografias, estilística e literatura. Haverá uma divisão de tarefas em que a sala deverá se comunicar para aprender. O aluno precisará utilizar a sua criatividade para expor o assunto por meio de datashow, internet, computador, slides, vídeos, dramatizações, músicas, entre outros recursos. No momento da Dramatização, os professores de Artes e Educação Física solicitarão a apresentação cênica de algumas manifestações populares brasileiras, convidando os alunos a experimentarem no corpo a construção de tais movimentos a partir de jogos de rimas, pelejas e disputas de improvisação e criação de personagens que se apresentaram em formato de poesia anteriormente, por meio da caracterização corporal. Já, no momento da utilização de Memes, o professor de Filosofia solicitará a representação dos personagens que despertaram mais a atenção dos alunos durante as leituras por meio de Memes para que possam fazer uso de sua imaginação para criar cenários.

Portanto, de acordo com os relatos obtidos e após analisar a resolução dos exercícios de aprendizagem efetivados pelos profissionais de educação que vivenciaram o curso em questão, acredita-se que este cumpre o seu propósito formativo. 
Acrescenta-se que os pesquisadores enfrentaram dificuldades no momento da aplicação deste curso devido ao período de interlocução remota mencionado anteriormente, pois muitos educadores alegaram que estavam sobrecarregados. Sendo assim, foi necessário um grande esforço para sensibilizá-los sobre a importância deste momento para a escola.

Como limitação deste estudo, cita-se a não generalização dos resultados descritos visto que a pesquisa ocorreu apenas em uma escola de Educação Básica pública. Sendo assim, recomenda-se que pesquisas futuras com o mesmo propósito de pesquisa sejam realizadas em outras escolas, incluindo as privadas, como forma de validar ou mesmo aprimorar o curso de qualificação docente desenvolvido.

\section{Referências}

Agra, G., et al. (2019). Análise do conceito de Aprendizagem Significativa à luz da Teoria de Ausubel. Rev. Bras. Enferm. 72 (1), $154-169$.

Albertin, A. L. (2000). Comércio Eletrônico Modelo, Aspectos e Contribuições de sua Aplicação. São Paulo: Atlas.

Anastasiou, L. G. C. (2015). Ensinar, aprender, apreender e processos de ensinagem. In: Anastasiou, L. G. C., Alves, L. P. (Org.). Processos de ensinagem na universidade: pressupostos para as estratégias de trabalho em aula. Joinvile: Univille.

Augustinho, E., \& Vieira, V. S. (2021). Aprendizagem significativa como alicerce para metodologias ativas no ensino de ciências: uma interlocução em prol da educação de jovens e adultos. Nova Revista Amazônica, 9 (1), 37-49.

Ausubel, D. P. (1963). The psychology of meaningful verbal learning. New York: Grune \& Stratton.

Ausubel, D. P. (2003). Aquisição e retenção de conhecimentos: uma perspectiva cognitiva. (1 ${ }^{\mathrm{a}}$. ed.): Paralelo Editora..

Brasil. Ministério da Educação. (217). Base Nacional Curricular Comum. Brasília, DF: MEC/SEF. http://basenacionalcomum.mec.gov.br/images/BNCC_EI_EF_110518_versaofinal_site.pdf>.

Bossi, K. M. L., \& Schimiguel, J. (2020). Metodologias ativas no ensino de Matemática: estado da arte. Research, Society and Development, 9 (4), 1-12

Brown, T., \& Wyaat, J. (2010). Design thinking for social innovation. Stanford Social Innovation Review, Winter.

Carotenuto, F. M., \& Pereira, O. J. (2020). Professores, metodologias ativas e a EAD: uma proposta prática da inversão da sala de aula utilizando a Pirâmide de William Glasser. http://www.abed.org.br/congresso2020/anais/trabalhos/52112.pdf.

Carril, M. G. P., Natário, E. G., \& Zoccal, S. I. (2017). Considerações sobre aprendizagem significativa, a partir da visão de Freire e Ausubel - uma reflexão teórica. Revista Multidisiplinar de Ensino, Pesquisa e Extensão e Cultura da UERJ, 6 (13), 35-47.

Diesel, A., Baldez, A. L. S., \& Martins, S. N. (2017). Os princípios das metodologias ativas de ensino: uma abordagem teórica. Revista Thema, 14 (1), 268288.

Distler, R. R. (2015). Contribuições de David Ausubel para a intervenção psicopedagógica. Rev. Psicopedag, 32 (98), 191 - 199.

Freire, P. (1987). Pedagogia do oprimido. Rio de Janeiro: Paz e Terra.

Freire, P.(1992). Pedagogia da Esperança: um reencontro com a Pedagogia do oprimido. Rio de Janeiro: Paz e Terra.

Freire, P. (1995). Política e educação. São Paulo: Cortez.

Freire, P. (1998). Pedagogia da autonomia: saberes necessários para a prática educativa. Rio de Janeiro: Paz e Terra.

Freire, P. (2011). Educação como prática da liberdade. São Paulo: Paz e Terra.

Gibbs, G. (2009). Análise de Dados Qualitativos. Porto Alegre: Artmed.

Godoy, A. S. (1995). A pesquisa qualitativa: tipos fundamentais. Revista de Administração de Empresas. São Paulo, 35 (3), $20-29$.

Honorato, C. A., Dias, K. K. B., \& Dias, K. C. B. (2018). Aprendizagem Significativa: uma introdução à teoria. Mediação, 13 , (1), $22-37$.

Lourenço, R. W., Alves, J. G. S., \& Silva, A. P. R. (2021). Por uma aprendizagem significativa: metodologias ativas para experimentação nas aulas de ciências e química no Ensino Fundamental II e Médio. Brazilian Journal of Development, 7 (4), 35037-35045.

Moran, J. (2018). Metodologias ativas para uma aprendizagem mais profunda. In: Bacich, L., Moran, J. (org.) Metodologias ativas para uma educação inovadora. Porto Alegre: Penso.

Moreira, M. A. (2011). Aprendizagem Significativa: a teoria e textos complementares. São Paulo: Editora Livraria da Física.

Moreira, M. A. Mapas Conceituais e Aprendizagem Significativa. (2013). I Workshop sobre Mapeamento Conceitual da USP, Paulo, 25-26 mar. http://50anos.if.ufrj.br/MinicursoMoreira_files/Moreira_aprendizagem_significativa_em_mapas_conceituais.pdf.

Moreira, M. A. (2014). Teorias de aprendizagem. (2a ed.): EPU. 
Research, Society and Development, v. 10, n. 14, e151101421752, 2021

(CC BY 4.0) | ISSN 2525-3409 | DOI: http://dx.doi.org/10.33448/rsd-v10i14.21752

Moreira, M. A., \& Masini, E. F. S. (2006). Aprendizagem significativa: a teoria de aprendizagem de David Ausubel. (2ª ed.): Centauro Editora.

Moreira, M. A., \& Masini, E. F. S. (2008). Aprendizagem significativa: a Teoria de David Ausubel. São Paulo: Centauro.

Mota, A., \& Werner, R. C. (2018). Ensaio sobre metodologias ativas: reflexões e propostas. Revista Espaço Pedagógico, 25 (2), $261-276$.

Neves, S., Rodrigues, L., Bento, P. S., Maranhão, S., \& Neves, I. J. (2017). Aprendizagem significativa por descoberta: uma reflexão da problematização sob a abordagem de Ausubel. Atas Investigação Qualitativa em Educação, 1 (1), 34-49.

Nogueira, M. O. G., \& Leal, D. (2015). Teorias de aprendizagem: um encontro entre os pensamentos filosófico, pedagógico e psicológico. 2 ed. Curitiba: InterSaberes.

Oliveira, A. C. A. de. (2014) A Contribuição do Design Thinking na educação. E-Tech: Tecnologias para Competitividade Industrial, Florianópolis, n. Especial Educação.

Pereira, J. C., et. al. (2011). Metodologias Ativas e Aprendizagem Significativa: Processo Educativo no Ensino em Saúde. Revista Ensino, Educação e Ciências Humanas, 22 (1), 11-19.

Santos, P. V. S., et al. (2017). A metodologia Design Thinking como estratégia gerencial para empreendimentos. Revista Latino-Americana de Inovação e Engenharia de Produção, 5 (8), 25-43.

Vasconcelos, M. L. M. C., \& Brito, R. H. P. (2014). Conceitos de educação em Paulo Freire. (6 ${ }^{\text {a }}$. ed.): Vozes.

Viana, M., et al. (2012). Design thinking: inovação em negócios. Rio de Janeiro: MJV Press. 